\title{
Analysis of Noise Exposure Measurements Acquired Onboard the International Space Station
}

\author{
José G. Limardo ${ }^{1}$ and Christopher S. Allen ${ }^{2}$ \\ NASA Johnson Space Center, Houston, Texas, 77058
}

\begin{abstract}
The International S pace Station (ISS) is a unique workplace environment for U.S. astronauts and Russian cosmonauts to conduct research and live for a period of six months or more. Noise has been an enduring environmental physical hazard that has been a challenge for the U.S. space program since before the Apollo era. Noise exposure in ISS poses significant risks to the cre wmembers, such as; hearing loss (temporary or permanent), possible disruptions of crew sleep, interference with speech intelligibility and communication, possible interference with crew task performance, and possible reduction in alarm audibility. Acoustic measurements were made onboard ISS and compared to requirements in order to assess the acoustic environment to which the crewmembers are exposed. The purpose of this paper is to describe in detail the noise exposure monitoring program as well as an assessment of the acoustic dosimeter data collected to date. The hardware currently being used for monitoring the noise exposure onboard ISS will be discussed. Acoustic data onboard ISS has been collected since the beginning of ISS (Increment 1, November 2001). Noise exposure data analysis will include acoustic dosimetry logged data from crew-worn dosimeters during work and sleep periods and also fixedlocation measurements from Increment 1 to present day. Noise exposure levels (8-, 16- and 24-hr), $L_{E Q}$, will also be provided and discussed in this paper. Future directions and recommendations for the noise exposure monitoring program will be highlighted. This acoustic data is used to ensure a safe and healthy working and living environment for the crewmembers onboard the ISS.
\end{abstract}

\section{Nome nclature}

$L_{A, 24}=24$-hour equivalent noise exposure levels

$L_{A, P K}=$ highest instantaneous noise level

$L_{A, T} \quad=$ noise exposure level, actual cre $\mathrm{w}$ wear times, $\mathrm{T}$

$L_{E Q} \quad=$ equivalent noise exposure levels

$L_{\max }=$ the loudest level the dosimeter was exposed to during the recording

$U \quad=$ expanded uncertainty

$u \quad=$ standard uncertainty

$u_{1} \quad=$ standard uncertainty, for sampling of job noise levels

$u_{2} \quad=$ standard uncertainty, for the instrumentation used

$u_{3}=$ standard uncertainty, for measurement (microphone) position

\section{Introduction}

$\mathrm{T}$

HIS paper presents an overview of the noise exposure assessment strategy used for monitoring the crewmembers onboard the International Space Station (ISS). The strategy included crew monitoring data collected from the work and sleep periods on ISS. The ISS is an orbiting laboratory in the low-earth-orbit that provides a facility for conducting science research. Science research is conducted in several pressurized modules. These include; the US Laboratory module, the European Space Agency's Columbus module, the Japanese Experiment module and the Russian's Service Module. Besides laboratory modules, ISS also includes three other modules called Nodes that connect the laboratory modules. Node 1 connects the United States On-Orbit Seg ments

\footnotetext{
${ }^{1}$ Deputy, Acoustics Office, Environmental Factors Branch, 2101 NASA Parkway/Mail Stop: SF22.

${ }^{2}$ Manager, Acoustics Office, Deputy, Environmental Factors Branch, 2101 NASA Parkway/Mail Stop: SF22.
}

1 
(USOS) to the Russian On-Orbit Segments (ROS). Node 2 connects the US, European and Japanese laboratory modules as well as berthing ports for docking. It also contains four sleeping crew quarters. The other two sleeping crew quarters are located in the Russian Service Module. Node 3 is attached to the port side of Node 1 and houses the life-support equipment which includes the ISS air revitalization, oxygen generation, and the water recovery system. Node 3 also accommodates one of the bathrooms for crew hygiene called the Waste Hygiene Compartment (WHC) and exercising equipment (treadmill and weight-lifting device). The other bathroom and exercising equipment is located in the Russian Service Module, see figure 1. The ISS facility is a large, complex spacecraft that must be maintained by its crew onboard ${ }^{1}$. As part of the ISS maintenance tasks, monitoring of the environ ment is

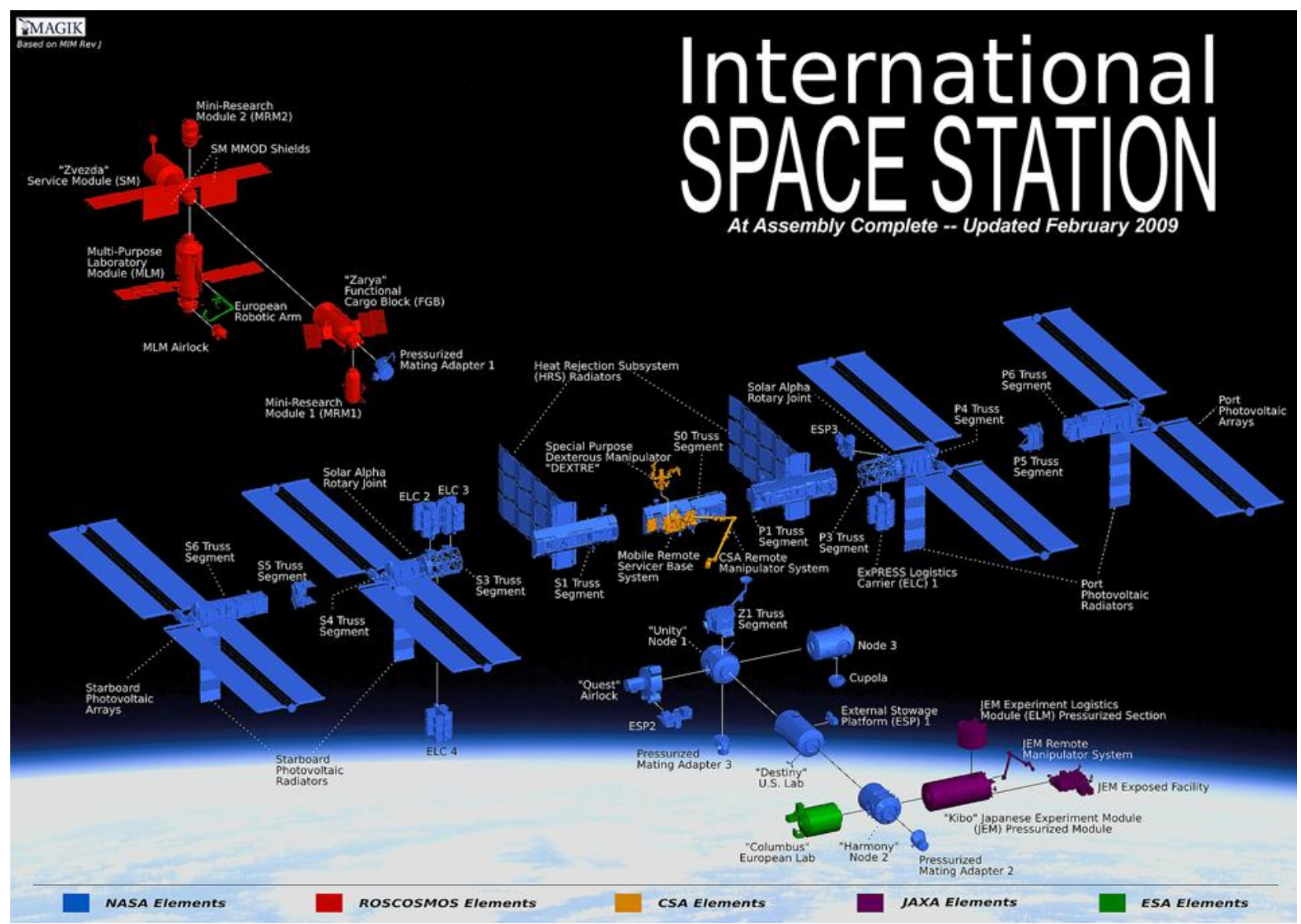

Figure 1. International S pace Station at Assembly Complete.

also accomplished by the crew, with all technical support provided by ground personnel. The space station was first occupied in November 2001. There were a total of three crewmembers onboard ISS during the intial stages. Later in October 2009 the permanent crew onboard ISS increased from three to six. The ISS crewmembers are rotated every four to six months. The period of time from the launch of the Soyuz Russian vehicle with the rotating ISS crewme mbers to the undocking from the station of the return vehicle of that same crew is called an ISS Increment.

These pressurized modules contain many equipment that generates noise. The noise exposure program has been in existence since the first ISS module was occupied. Noise exposure in ISS posed significant risks to the crewmembers, such as; hearing loss (temporary or permanent), possible disruptions of crew sleep, interference with speech intelligibility and communication, possible interference with crew task performance, and possible reduction in alarm audibility. Before we can discuss the details of the noise exposure data, we need to provide some information with regards to the ISS acoustic emission requirements, hardware used onboard ISS for noise monitoring, and how we train the crew to conduct the noise monitoring on ISS. 


\section{Requirements}

Acoustic emission measurements were made onboard the ISS in order to assess the acoustic environment to which the crewme mbers were exposed. This data was used to ensure a safe working and living environment for the crew as well as determine when actions were required in order to reduce the noise onboard the ISS. These requirements were documented in the Medical Operations Requirements Document ${ }^{2}$ (MORD), the Medical Requirements Integration Document $^{3}$ (MRID), the Generic Groundrules and Constraints Document ${ }^{4,5}$ (GGR\&C), the Increment Definitions and Requirements Document ${ }^{6}$ (IDRD) and from the Noise Level Constraint ISS Flight Rule (JSC Flight Rule B13$152)^{7}$, see table 1 . If 24 -hour crew-worn noise exposure levels $\left(\mathrm{L}_{\mathrm{A}, 24}\right)$ measured by the ISS acoustic dosimeters were $67 \mathrm{dBA}$ or higher, then the crewmembers were required to wear approved hearing protection devices according to the ISS Flight Rule. Table 1 was taken from JSC Flight Rules - B13-152, and was devised to prevent the crew from

Table 1. Noise Exposure Level us. Hearing Protection.

\begin{tabular}{lccccccccccc}
\hline \multicolumn{1}{c}{$\mathrm{L}_{\mathrm{A}, 24}$} & $65-66$ & 67 & 68 & 69 & 70 & 71 & 72 & 73 & $74-75$ & $76-77$ & $>78$ \\
\hline $\begin{array}{l}\text { Hrs/day } \\
\text { of hearing } \\
\text { protection } \\
\text { (in addition to } \\
\text { exercise period) }\end{array}$ & 0 & 2 & 7 & 11 & 14 & 16 & 17 & 19 & 20 & 21 & 22 \\
\hline
\end{tabular}

developing hearing loss. Adherence to these guidelines should keep the sound energy levels to which the ear was exposed at an acceptable level. Use of hearing protection was recommended when working in the Russian Service Module, when exercising on the treadmills, and when exposed to higher noise levels. NASA and the Johnson Space Center's Acoustics Office developed and implemented acoustic requirements that must be met for hardware and payloads to be certified for spaceflight. This was the first step in the noise control process for the International Space Station $^{8}$. The acoustic requirements were based on the U.S. Noise Criterion (NC) family of curves ${ }^{9}$. The pressurized modules on ISS have an acoustic requirement of NC-50. The non-integrated government furnished equipment (e.g. exercise equipment) within the modules must meet the NC-40 criterion. The ISS payload requirements were set to NC-34. The rack that houses the payloads have an acoustic requirement of NC-40 and the total complement of payloads inside a given pressurized module were required to meet NC-48 criterion. All of these allocations were provided at all hardware levels in order to ensure a safe and healthy working and living environment for the crewmembers onboard the ISS. Detailed information regarding the acoustic requirements on ISS is documented in another paper ${ }^{10}$.

\section{Noise Monitoring Hardware/Crew Training}

\section{A. Monitoring Har dware}

Acoustic dosimeters were instruments used to measure noise exposure over extended periods of time. The instruments used on orbit during ISS Increments 1-15 were the Ametek Mark I Audio Dosimeters, see figure 2. A total of three acoustic dosimeters were onboard ISS at all times. The Mark Series featured simple pushbutton operation. Pressing a button sequentially displayed sampled data without disrupting the sampling process. Status indicators allowed the user to see at a glance that the unit was operating or if the battery needed to be changed. The instruments also included a large, easy-to-read display. A microphone on a cable was also included allowing the microphone to be clipped to the crewmembers' collar. The instrument conformed to S2A accuracy requirements in ANSI S1.4-1983, and IEC 60651. The dosimeters can either be worn or hung in a static location to determine noise exposure, equivalent sound pressure level, in dBA. The measurement period used during an ISS Increment was

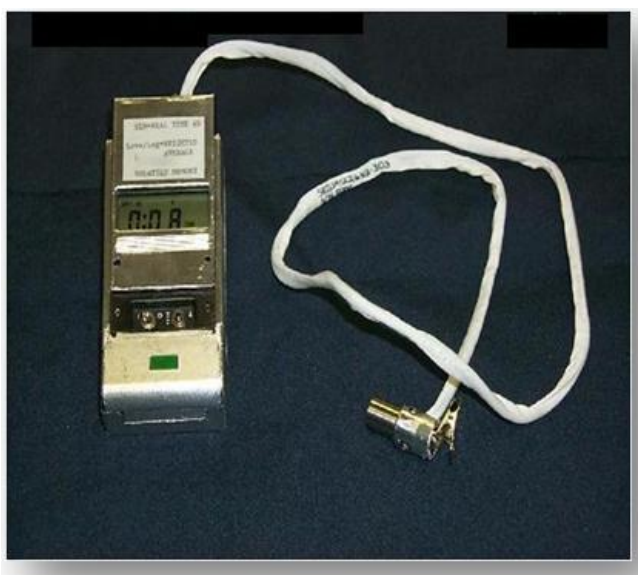

Figure 2. Ametek Mark I Audi o Dosimeter. 24-hours. The sessions were split into a 16-hour workday and an 8-hour sleep period. These values were then combined mathematically into an equivalent 24-hour exposure level. The dosimeter also recorded other levels such as $\mathrm{L}_{\max }$, the loudest level the dosimeter was exposed to during the recording period. The batteries were changed 
before each operation because they last 40 hours nominally. There was no mechanism in place to calibrate the dosimeters once they're on-orbit. The dosimeters were sent to the vendor for calibration each year, and a similar approach was used for re-supply before they leave the ground at launch minus seven months. However, these

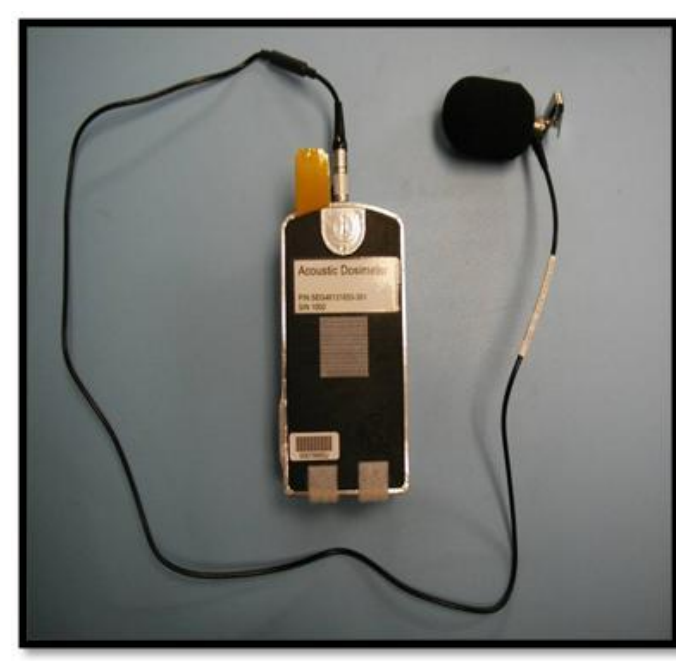

Figure 3. Quest NoisePro-DLX1 Dosimeter with protective cover. dosimeters provided one number per measurement session and required the crew to provide hand-tabulation of data which then was called down to Mission Control by the crew. The data provided by this dosimeter was difficult to interpret because single events were unidentifiable.

During the summer of 2008, the audio dosimeter was replaced with a Quest NoisePro DLX-1 acoustic dosimeter, see figure 3. This new acoustic dosimeter had many capabilities and features. The Quest NoisePro DLX-1 dosimeter was a battery powered (2AA alkaline), programmable acoustic dosimeter using a backlit 128 x 64 pixel graphical Liquid Crystal Display (LCD) and was programmable to measure audio levels in three user selectable measurement ranges (40-110 dB RMS, 70-140 dB RMS and 115$143 \mathrm{~dB}$ Peak). The dosimeter also had five frequency weighting profiles (RMS A, RMS C, Peak A, Peak C and Peak Z). The internal non-volatile me mory allowed for a maximu $\mathrm{m}$ of 40 hours of data storage. This dosimeter was capable of providing dBA values for each one-minute interval during the selected sampling period. Data can also be recalled on the display or downloaded via infrared serial interface. This dosimeter had many technical and operational benefits. The data-logging feature provided an accurate account of crewme mber noise exposure history. This feature made noise exposure data easy to interpret. The dosimeters had a calibration life of two years set by the vendor prior to each flight to ISS, regardless of the advertised calibration life span of two years. The newly calibrated dosimeters were exchanged for those that have been in use since the last supplied flight. The dosimeter was supplied to ISS with a protective cover that protected the entire face of the dosimeter. This cover was attached to the face of the acoustic dosimeter using hook and loop fasteners. Clear medical tape was also applied to the LCD screen to aid in the containment of shatterable materials in the event the LCD screen was impacted. When the acoustic dosimeter was mounted in the static location, the protective cover was secured to the face of the acoustic dosimeter and the dosimeter was mounted with the hook and loop fasteners facing the wall to provide an additional level of protection.

The crewmembers wore the acoustic dosimeters for a continuous 24 hour period to measure typical exposures to noise on ISS. The device was stored in a pocket or clipped to the crewmembers clothing. The microphone had a

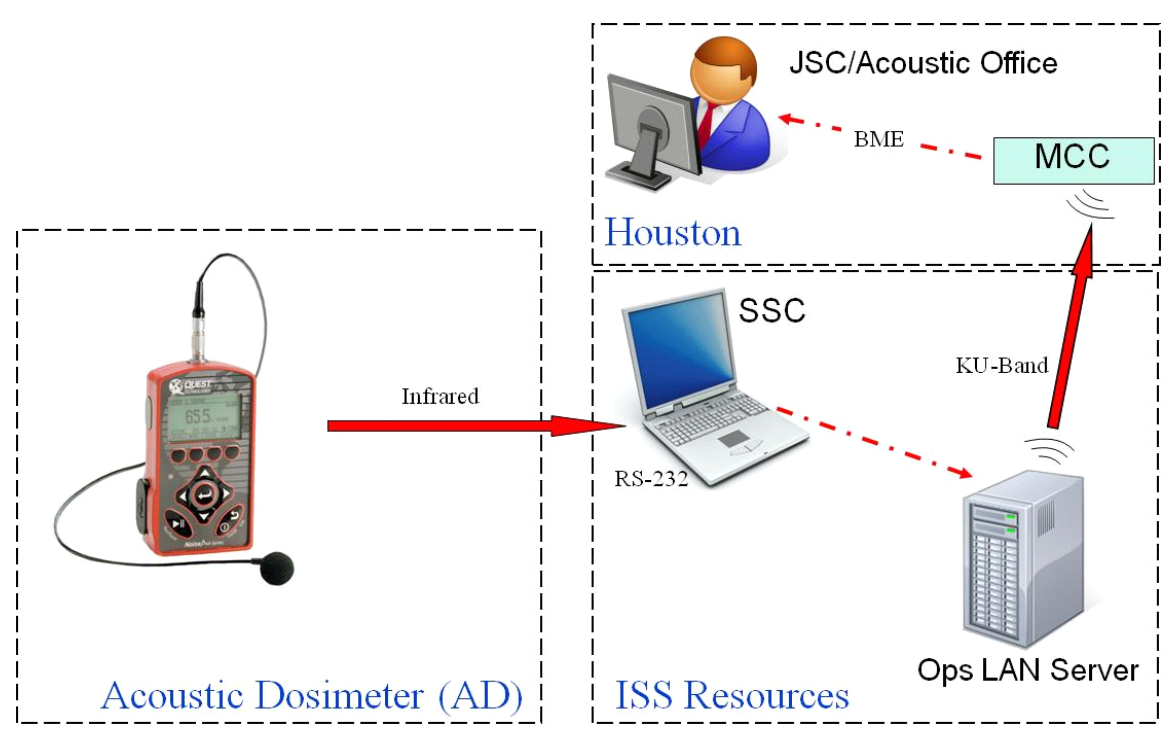

Figure 4. Acoustic Dosimeter Data Downl oad Process. separate clip allowing placement on the collar or lapel so that was it in close proximity to the crewme mbers ear. The acoustic dosimeter was also attached at a static location in the ISS to collect noise levels in locations onboard ISS. Data can be recalled on the display and transferred to the Space Station Computer (SSC) via infrared serial interface, see figure 4. The acoustic dosimeter was used to measure and monitor crew exposure to ambient noise as they performed nominal activities and tasks throughout ISS. This monitoring was also used to 
characterize the internal acoustic environment of ISS, to ensure that hardware acoustic levels had been met, and to assist in the implementation of effective countermeasures to reduce or eliminate crew exposure to high noise levels. As part of nominal on-orbit operations, the acoustic dosimeter ran for 48 hours increments ( 24 for crew-worn and 24 for static locations). The acoustic dosimeter collected data that was then transferred to the SSC. Before a second 48 hour increment had begun, the crew replaced the two AA alkaline batteries in each of the acoustic dosimeters. The batteries required for operation were acquired from the ISS battery pantry. Before the two year calibration life expired, three new acoustic dosimeters were supplied to ISS. The dosimeters were returned to ground on the Space Shuttle for refurbishment, but after the Shuttle retires they will be disposed of and replaced with new dosimeters every two years. The acoustic dosimeters were calibrated and functionally tested prior to and after flight, when possible (if returned to ground), using a sound level meter calibrator. Once the pre-flight calibration and functional testing was completed, the batteries used in the test were removed and disposed of before flight. No on-orbit maintenance was required on the acoustic dosimeters. All major calibrations and maintenance activities done to the acoustic dosimeters were completed on the ground.

\section{B. Crew Training}

Environmental monitoring was one of the key tasks required by all crewmember onboard ISS in order to maintain a healthy and safe environment. On-orb it crewtime was a high de mand asset for all operational tasks. Many environmental monitoring tasks were very time consuming while others were not. The acoustic dosimetry monitoring task was performed by one crewmember, see figure 5. This crewmember must deploy the dosimeters (either crew-worn or static location), download the data from the dosimeter into the Space Station Computer and later stow the dosimeters back into the kit. This activity was performed once a month. All crewmembers were trained for acoustic dosimeter measurements prior to flight. Training included nominal operation of the acoustic dosimeter hardware, software handling and operational and malfunction procedures. Some crewmembers also participated in the validation process of the operational procedures. They reviewed the procedures and provided suggestions on how to clarify and simplify the steps which helped reduce on-orbit crewtime. Crewmembers may request refresher training prior to flight if they feel its warranted ${ }^{3,11}$. The crewmembers were also trained on how to effectively use the different types of hearing protection devices available to them onboard ISS. The hearing protection devices (passive and active) that were available to the crewme mbers included; foam ear inserts, custom (molded) earplugs, and active noise reduction (ANR) headsets ${ }^{12}$. Several sizes, depending on crew preference, of the foam ear inserts were provided to the crewmembers. These ear foam inserts were worn at the crew discretion and then trashed when the crew was done wearing them. Two types of custom earplugs were molded to each specific crewmember's ear canal and provided to each ISS crewmember. The first custom earplug included filters for lowering sound levels. A prime ( $25 \mathrm{~dB}$ filter) and a spare (15 dB filter) custom earplug, for each crewmember, were sent to ISS at the same time. The second type of custom earplug provided to the ISS crew was primarily used for performing on-orbit hearing assessments for evaluating the crew's onorbit hearing. These custom earplugs were also used for attenuating ambient sound levels (up to $37 \mathrm{~dB}$ ). Additionally, each crewmember was equipped with an active noise reduction headset. Several ANR

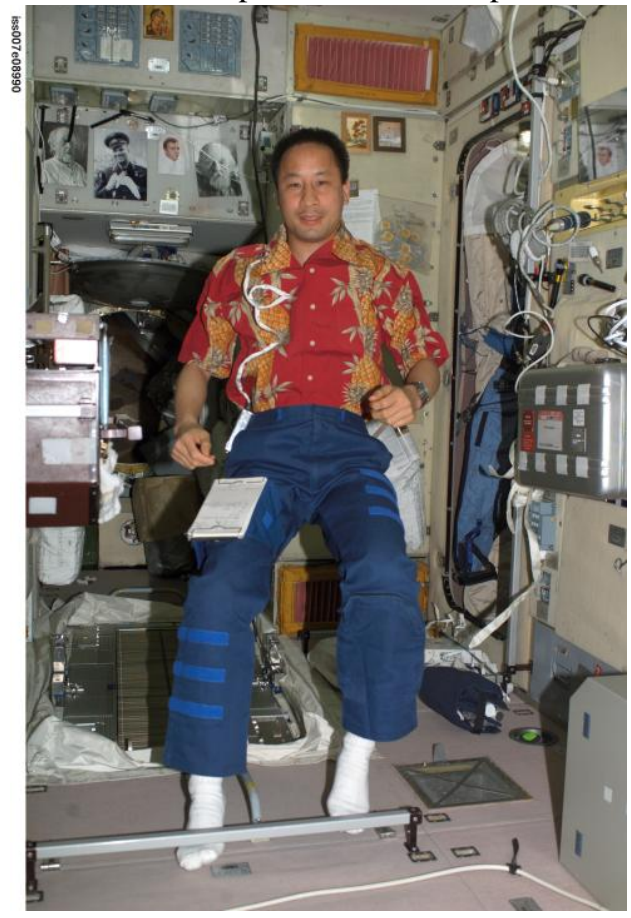

Figure 5. Astronaut Edward T. Lu, Expedition 7 NASA ISS science officer and flight engineer, wearing an acoustic dosimeter in the Russian Service Module on the International Space Station (ISS). headset spares were also available on ISS. The ANR headset used on ISS was the Bose® Quiet Comfort ${ }^{\circledR} 2$ Headphone (cancels low frequency noise in bandwidths below $750 \mathrm{~Hz}$ ). The ANR headset can also be used as a passive hearing protection device. However, the prolonged use of hearing protection devices could have health implications. Some crewmembers have reported discomfort, such as; constant irritation in their ear canals or the pressure from the headsets ${ }^{13}$. The hearing protection devices were not intended for extended use on ISS. Noise control mitigation strategies on noisy hardware are the first line of defense on ISS. 


\section{Data and Analys is}

\section{A. Acoustic Dosimetry}

Acoustic dosimetry data included crew-worn and static location measurements. The acoustic dosimeter activity was divided into two days; (1) crew-worn measurements during the first day and (2) static measurements the following day. The frequency of these activities was monthly with static measurements performed every other month. For the crew-worn activity, the crewmember donned the acoustic dosimeter and started the measurement before breakfast during the day of the planned activity. The crew-worn session concluded immediately before post sleep activities the following day. The crew-worn session included day time and sleep time periods (24-hours). For the static measurement session, the crewmember deployed the acoustic dosimeters in predetermined locations (three) during the $2^{\text {nd }}$ day of the acoustic dosimeter activity. The static locations included specific areas in the modules or in the vicinity of specific hardware (e.g. near the treadmill or fans) for conducting assessments and evaluations. These locations were selected by the Johnson Space Center's (JSC) Acoustics Office and were rotated throughout ISS for trending purposes. After completing the crew-worn and static measurements, the data was then transferred from all three dosimeters to the Space Station Computer (SSC) and downlinked via the Orbital Communications Adapter (OCA) as shown in figure 4. The following paragraphs will discussed the crew-worn and static location measurements.

\section{Crew-worn measurement}

The crewmembers donned acoustic dosimeters before breakfast on the day of the acoustic dosimetry activity for the duration of 24 hours to record the work-day and sleep period data, see figure 5. The 24-hour equivalent noise exposure levels, $\mathrm{L}_{\mathrm{A}, 24}$ or $\mathrm{L}_{\mathrm{EQ}}$, given in Table 2, as an example, reflects the actual crew-wear times, $\mathrm{T}$. All noise exposure levels were recorded using the $5-\mathrm{dB}$ exchange rate $(\mathrm{ER})^{14} . \mathrm{L}_{\mathrm{A}}$, $\mathrm{T}$ was the equivalent noise exposure level

Table 2. Crew-Worn Acoustic Dosimetry Data (Example).

\begin{tabular}{|c|c|c|c|c|c|c|c|}
\hline \multirow[b]{2}{*}{ Activity } & \multirow[b]{2}{*}{$\begin{array}{c}\text { Acoustic } \\
\text { Dosimeter } \\
\text { Serial No. }\end{array}$} & \multirow[b]{2}{*}{$\begin{array}{l}\text { LA,24 } \\
{[\mathrm{dBA}]}\end{array}$} & \multirow[b]{2}{*}{$\begin{array}{c}\text { Crewmember } \\
\text { Location }\end{array}$} & \multicolumn{3}{|c|}{ Recorded Parameters } & \multirow{2}{*}{$\begin{array}{c}\text { Hearing } \\
\text { Protection } \\
\text { Requirement } \\
\text { [hours] }\end{array}$} \\
\hline & & & & $\begin{array}{l}\text { LA, T } \\
{[\mathrm{dBA}]}\end{array}$ & $\begin{array}{l}\text { LA, PK } \\
\text { [dBA] }\end{array}$ & $\begin{array}{c}\mathrm{T} \\
\text { [hours:min] }\end{array}$ & \\
\hline \multirow{6}{*}{ 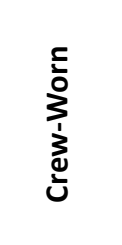 } & \multirow{2}{*}{1011} & \multirow{2}{*}{61} & Work (LEQ-16) & 64 & 121 & $13: 16$ & \multirow{2}{*}{0} \\
\hline & & & Sleep (LEQ-8) & 50 & 113 & $8: 29$ & \\
\hline & \multirow{2}{*}{1012} & \multirow{2}{*}{67} & Work (LEQ-16) & 70 & 128 & $13: 59$ & \multirow{2}{*}{2} \\
\hline & & & Sleep (LEQ-8) & 53 & 109 & $7: 30$ & \\
\hline & \multirow{2}{*}{1013} & \multirow{2}{*}{62} & Work (LEQ-16) & 65 & 125 & $14: 41$ & \multirow{2}{*}{0} \\
\hline & & & Sleep (LEQ-8) & 54 & 110 & $7: 26$ & \\
\hline
\end{tabular}

during the work and sleep time periods. $\mathrm{L}_{\mathrm{A}, \mathrm{PK}}$ was the highest instantaneous noise level measured during the measurement period. Required use of hearing protection was given in Table 2 in the far right column, based on the Flight Rule B13-152, see table 1. Per recommendations of the Multilateral Medical Operations Panel (MMOP) Acoustics Sub-Group, the 3-dB exchange rate will, in the future, be used instead of a 5-dB exchange rate when measuring noise exposures on ISS. The 3-dB exchange rate had been adopted by the National Institute of Occupational Safety and Health (NIOSH) and was used internationally ${ }^{15}$. The current acoustic dosimeter had the capability for recording the noise data using both exchange rates. For reference only until the new ISS Acoustic Flight Rule update is approve, the acoustic dosimetry data was also reported using the 3-dB exchange rate. The acoustic dosimeter also had the capability for logging data. An example of a crew-worn acoustic dosimeter logged data can be seen in figure 6. The work-day and sleep periods were easily distinguishable from each other. Work to correlate/match the acoustic dosimeter logged data with the crew task/activity is an on-going task. In figure 6, the cumulative $\mathrm{L}_{\mathrm{A}, 24}$ had also been plotted against the acoustic dosimeter logged data using both 3- (dotted line) and 5$\mathrm{dB}$ (solid line) exchange rates, respectively. This logged data provided information with regards to the overall crew noise exposure. As it can be seen in the graph, several crew tasks/activities were above $80 \mathrm{dBA}$ but below the hazard level of $85 \mathrm{dBA}$. Overall, based on the current ISS Acoustic Flight Rule, this particular crewmember was exposed to noise level of $69 \mathrm{dBA}$ which required wearing hearing protection for 11 hours based on the ISS Acoustic Flight Rule (see Table 1). This hearing protection requirement only applied to the crewmember wearing the acoustic dosimeter. Crew-worn dosimetry data on ISS had been collected since Increment 1 for trending purposes, see figure 7. This data was based on all crewmembers who were a long-time resident in ISS since November 2001. Based on the trend

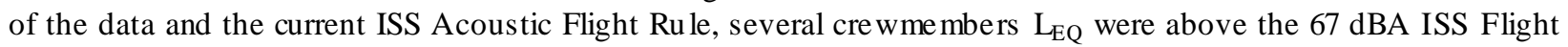

6

American Institute of Aeronautics and Astronautics 


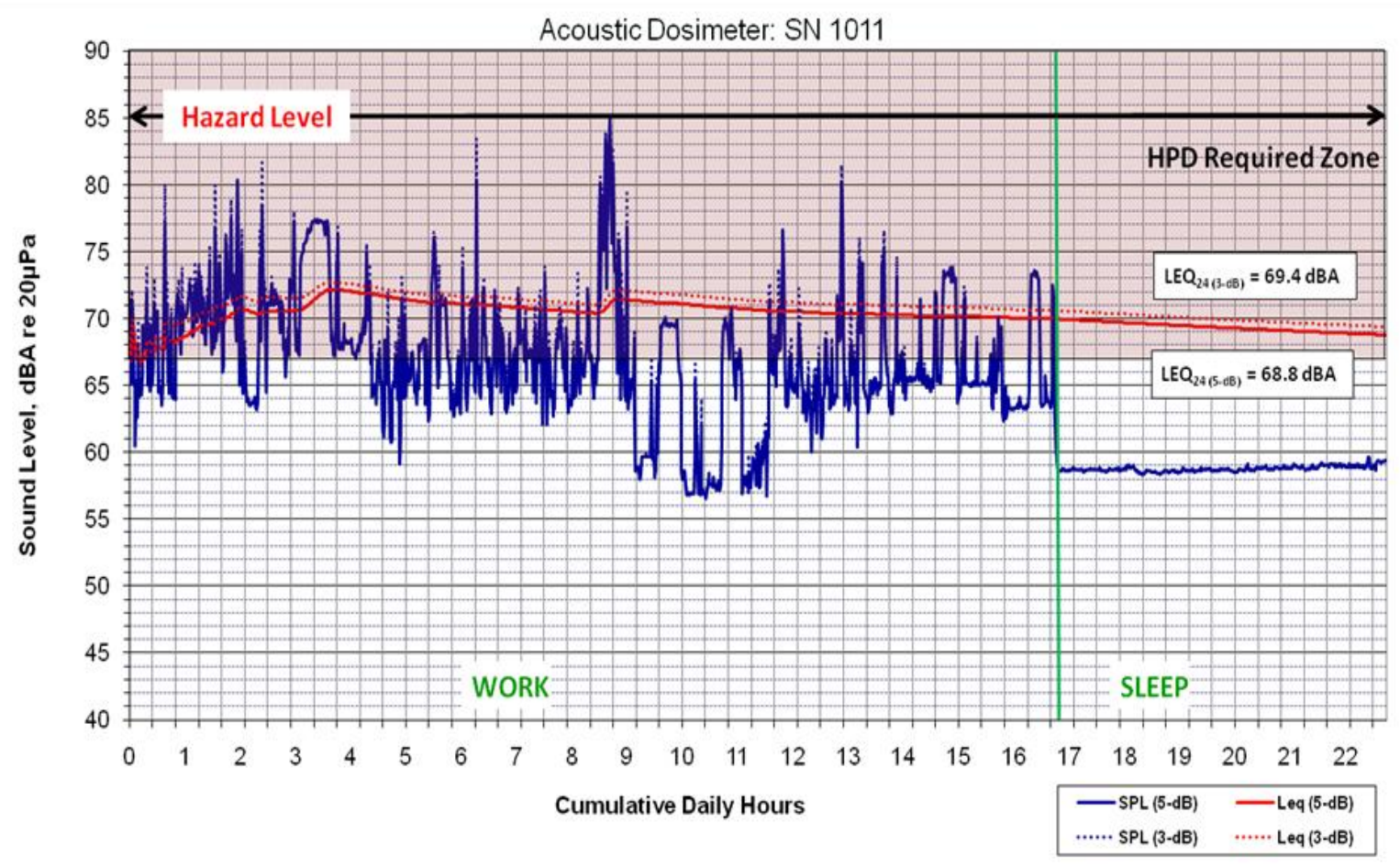

Figure 6. Crew-worn Acoustic Dosimeter Logged Data.

Rule level. Since Increment 20, more crewmembers $\mathrm{L}_{\mathrm{EQ}}$ levels had been below the ISS Flight Ru le. This was mostly based on the noise control strategies applied to equipment and hardware deployed in ISS. Noise control mitigations are an on-going effort enforced by the Johns on Space Center Acoustics Office. The equivalent noise exposure level for the work period was dependent on where the crewme mbers spend most of their time. The crewme mber can work on the Russian segment, the US segment or spend time working equally on both segments, see figure 8 for a distribution of $\mathrm{L}_{\mathrm{EQ}}$ during work hours. The data showed that the crewmembers who worked in the Russian segment were exposed to higher noise levels than crewmembers who worked in the US seg ment.

The crew quarters were designed to provide a personal, private area for a crewmember to use for rest, sleep, and work and for personal activities. Work activities included reading/writing, computer usage, and review of reports and procedures. Personal activities included changing clothes, reading/writing, and computer usage for watching movies or

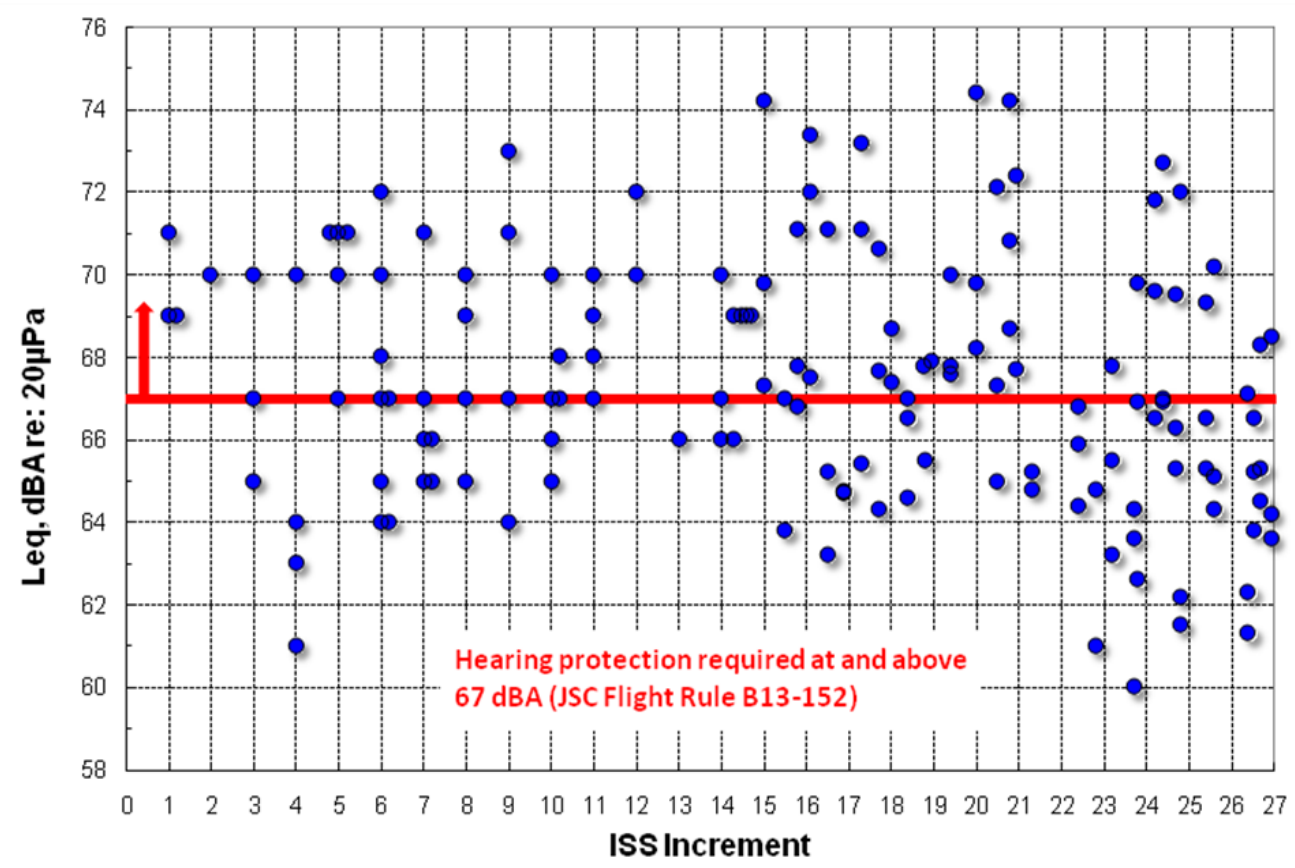

Figure 7. 24-Hour Crew-worn Dosimetry vs. ISS Increment. 


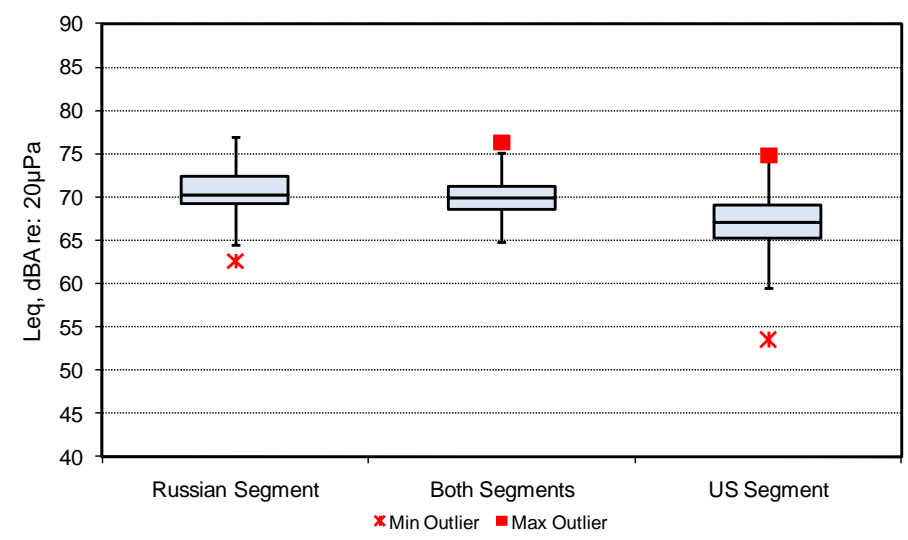

Figure 8. Distribution of $\mathrm{L}_{\mathrm{EQ}}$ during work hours by location. writing emails, listening to music, personal communication, and private medical consultations. It also provided limited stowage for personal items, clothing, and computer accessories. Design features included isolation from exterior light and noise as well as reduction of exposure to space radiation and it also provided a thermal environment and internal illumination that is comfortable and adjustable $^{16}$. The Temporary Sleep Station (TeSS) was provided to ISS during Increment 2 to accommodate the third crewmember. The other two crewmembers slept in the Russian crew quarters (Port and Starboard Kayuta). The TeSS was the precursor to the US crew quarters (CQs); it did not have an adjustable ventilation system or an alarm annunciation system. The TeSS was deployed in the US Lab and later retired as a sleep station once the four permanent US crew quarters were supplied to ISS. All four US crew quarters were located in Node 2. It has been estimated that long-duration crewmembers can expect to spend one-third of their entire mission inside a crew quarter.

The ISS crew quarters sleep stations provided a quiet area for recovery (reduced acoustic stimulus to the ears) from daytime noise exposure levels. This recovery period was very similar to the recovery period promoted by the Occupational Safety and Health Administration (OSHA) for occupational noise exposure without hearing protection compared to the ISS Flight Rule ( 85 versus $65 \mathrm{dBA}$ ). The only difference was that OSHA's limits were based on workers who were to high levels of noise during the 8-hour workday followed by 16 hours of auditory recovery for a 40-hour workweek followed by two days of auditory rest. In the case of the ISS crewmembers, they were exposed constantly to the daytime noise exposure levels whenever they are not inside their sleeping cre w quarters.

The two Russian crew quarters (Port and Starboard), referred to as Kayutas, and were located in the Russian Service Module. The Russian segment tends to be one of the noisiest modules in ISS, and crewme mbers sleeping in the Kayutas generally had to wear hearing protection devices while sleeping due to high noise levels. Initially, the Kayutas were designed with a porthole and without a door. As ISS was assembled, a door was later provided and installed to the Kayutas as well as noise control mitagations to Russian segment hardware components. The crew quarters used during the NASA-Mir Program also did not have any door. Many of the crewmember's comments were related to the lack of door on the crew quarter, preventing noise and light from entering the sleep station ${ }^{17}$. Due to the noise control strategies, noise levels in the Kayutas have decreased on the average by approximately $10 \mathrm{dBA}$ since levels first recorded in November 2001, see figure 9 . No ise levels have been recorded as high as above $70 \mathrm{dBA}$ during Increment 6 and as low as below $50 \mathrm{dBA}$ during Incre ment 25.

The ISS crew's sleep-time noise exposure levels for crew quarters located in the US segment are shown in figure 10. During ISS early stages, when the permanent US crew quarters were not available, crewme mbers also slept in
Figure 9. Sleep Dosimetry vs. ISS Increments (Russian Segment).

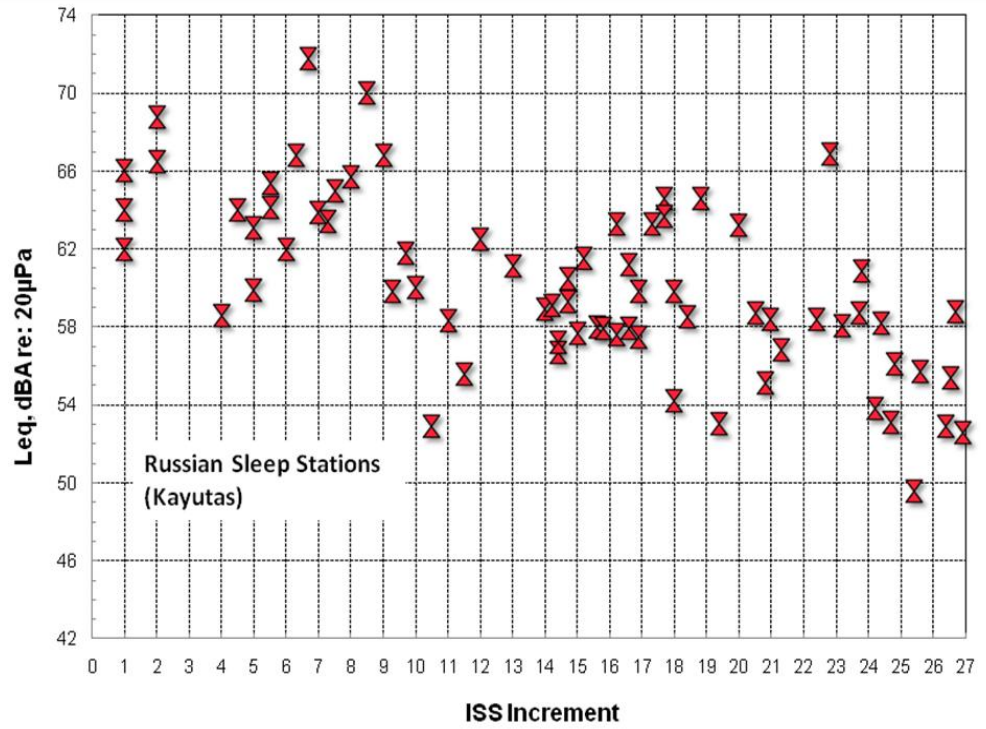

8

American Institute of Aeronautics and Astronautics 


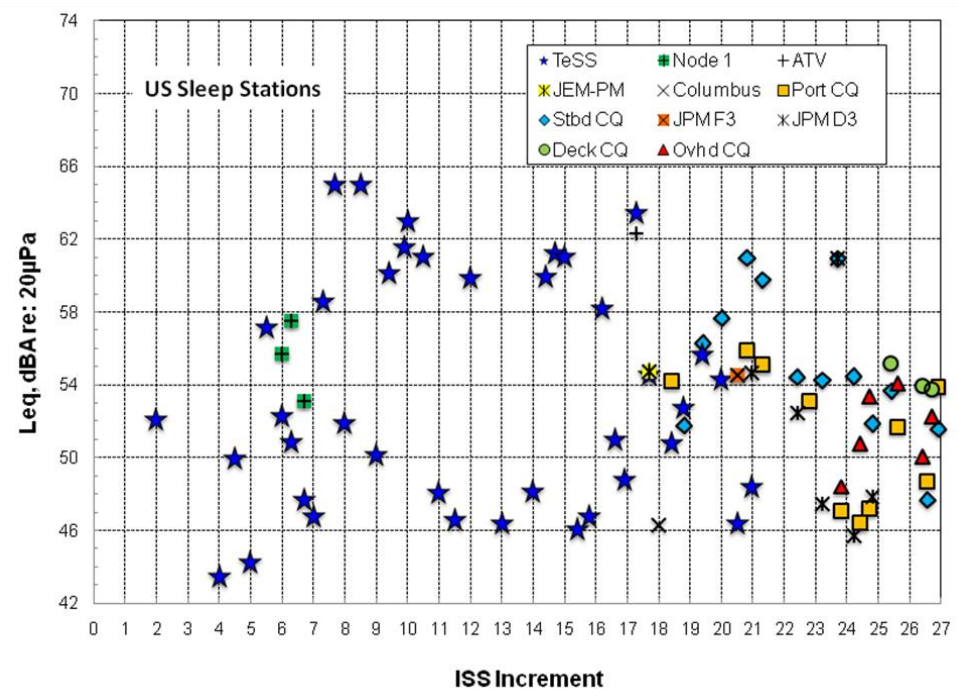

Figure 10. Sleep Dosimetry vs. ISS Increments (US Segment). the TeSS (located in the US Lab), and in locations within the other pressurized modules such as Node 1, Japanese Pressurized Module (JPM), the Columbus module and even in a visiting vehicle. These locations were all temporary. The four permanent US crew quarters (Port, Startboard, Deck and Overhead) became available to ISS crewmembers starting on Increment 18. Currently, there were a total of six crew quarters, two Russian (Kayutas) crew quarters (Port and Starboard) located in the Russian Service Module and the four US crew quarters located in the Node 2 module. The US and Russian crew quarters were adequately quiet to provide hearing rest and did not caused an increase risk for hearing loss. The exceedances of the sleep requirements (US: $49 \mathrm{dBA}$ and Russian: 50 dBA) were an increased risk to restful sleep.

However, crew debriefs indicated that crew sleep had not been effected by ISS sleep station noise levels. Different types and sizes of hearing protection devices were always available to all crewmembers on ISS if needed to help mitigate this risk. Figure 11 shows the distribution of $\mathrm{L}_{\mathrm{EQ}}$ levels during sleep hours. The data showed that the noise levels in the Kayutas in the Russian segment were higher than the crew quarters in the US segment with the noise levels for the TeSS in between the US and Russian crew quarter levels. This followed the same trend from figure 8, where crewmembers working in the Russian segment were exposed to higher noise levels than crewmembers working in the US segment.

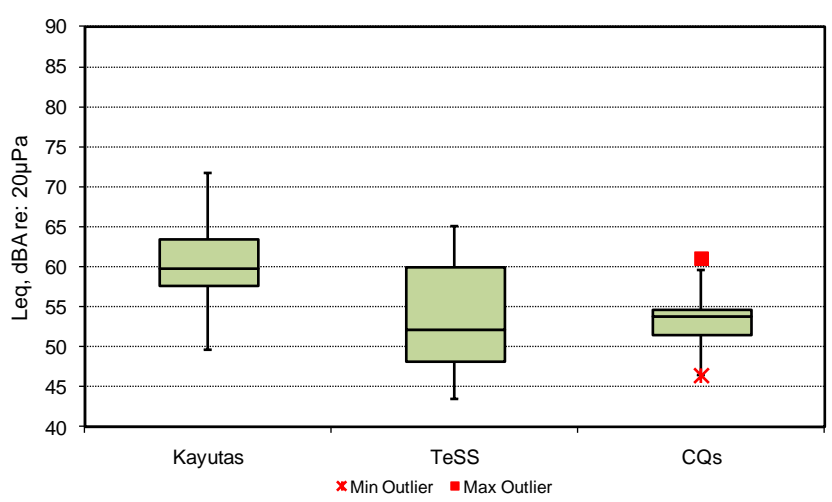

Figure 11. Distribution of $\mathbf{L}_{\mathrm{EQ}}$ during sleep hours by location.

The distribution of $\mathrm{L}_{\mathrm{EQ}}$ levels for both work hours and sleep-time hours including the full-day levels are shown in figure 12. The data showed that ISS crewmembers were exposed to higher noise levels during the work period

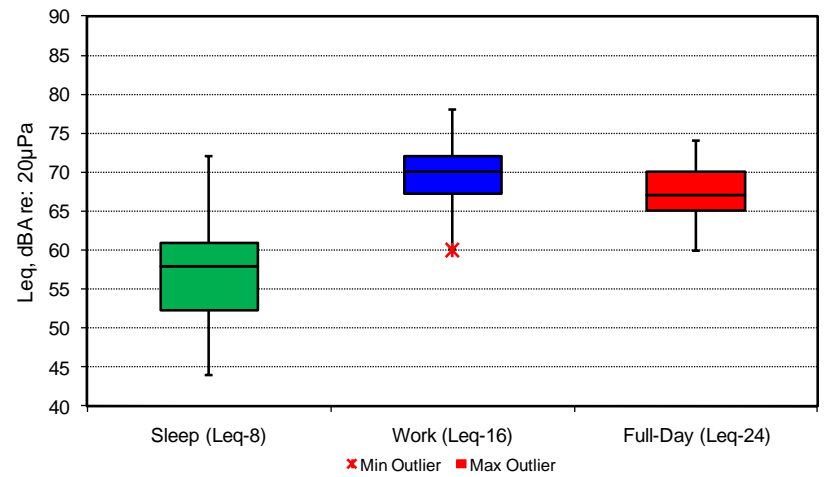

Figure 12. Distribution of $\mathrm{L}_{\mathrm{EQ}}$ by time of day.
( $\left.\mathrm{L}_{\mathrm{EQ}-16}\right)$, as compared to the sleep-time noise exposure levels $\left(\mathrm{L}_{\mathrm{EQ}-8}\right)$. The work period equivalent noise exposure level had a median level of $70 \mathrm{dBA}$, ranging from 60 to $78 \mathrm{dBA}$. As mentioned previously, crewmembers in the Russian segment were exposed to higher levels than any other segment in IS S. This was indicated by the higher equivalent noise exposure levels recorded during work hours. The sleep-time noise exposure levels had a median level of $58 \mathrm{dBA}$, ranging from 44 to $72 \mathrm{dBA}$. This $28 \mathrm{dBA}$ difference was mainly due to the difference in noise levels between the Russian and US segments, where the crew quarters were located, and also by the design differences between the US and Russian crew quarters.

After reviewing the trend on the average equivalent noise exposure level data, we concluded that the equivalent noise exposure levels for the full-day ( $\left.\mathrm{L}_{\mathrm{EQ}-24}\right)$ were very dependent on the noise levels from the work period ( $\mathrm{L}_{\mathrm{EQ}-16}$ ), see figure 13. The equivalent noise exposure levels during the work hours $\left(\mathrm{L}_{\mathrm{EQ}-16}\right)$ played a major role to the full-day 


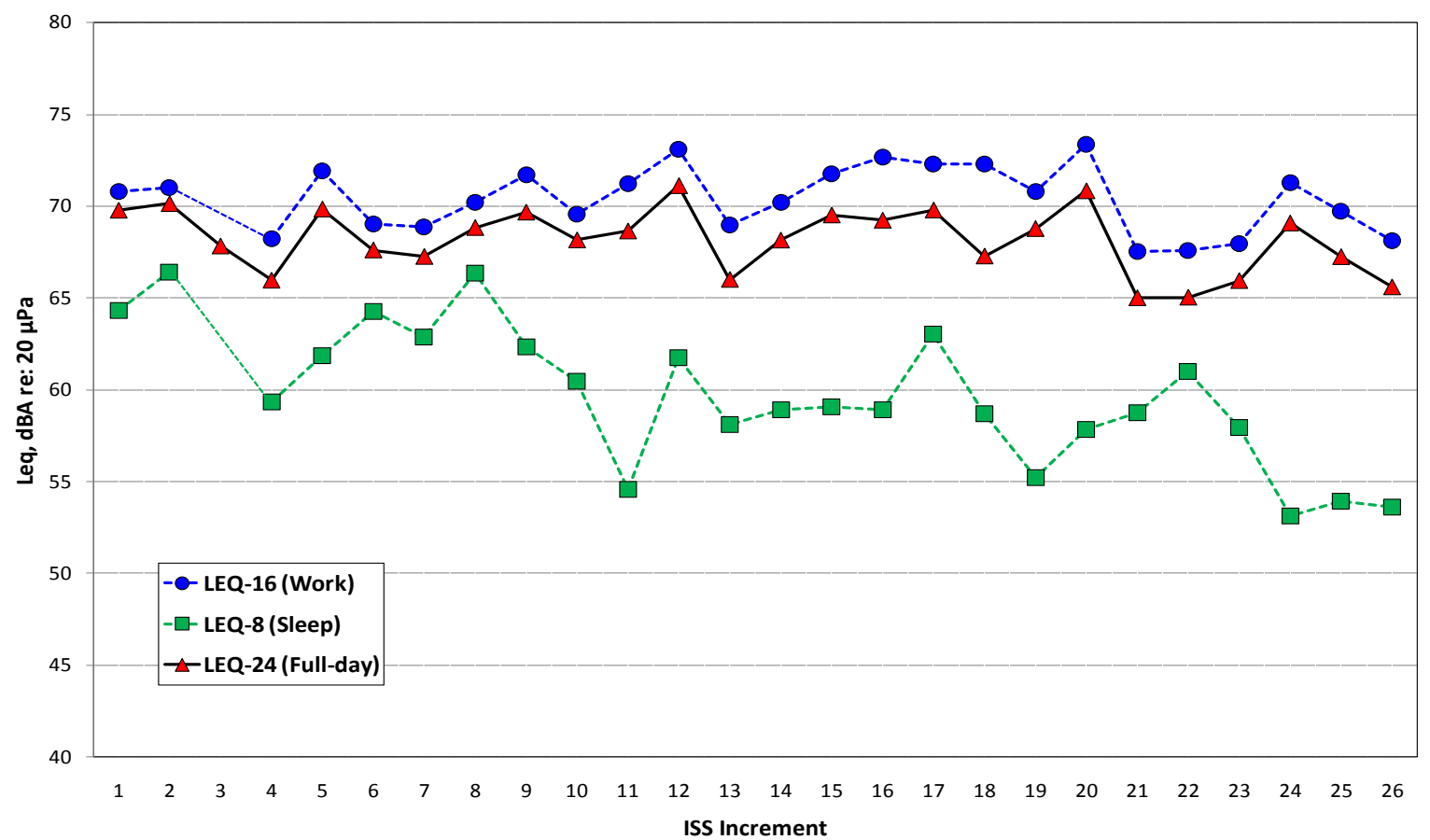

Figure 13. Crew-worn Acoustic Dosimetry (Average $\mathbf{L}_{\mathrm{EQ}}$ per ISS Increment).

equivalent noise exposure level ( $\mathrm{L}_{\mathrm{EQ}-24}$ ) when compared to the sleep-time levels ( $\mathrm{L}_{\mathrm{EQ}-8}$ ). The work and full-day equivalent noise levels were fairly constant throughout all 26 ISS Increments. The average equivalent noise exposure levels for the work hours fluctuated from 67 to $73 \mathrm{dBA}$ while the average noise levels for the full-day ranges from 65 to $71 \mathrm{dBA}$. The average noise exposure levels for the sleep-time period, however, have decreased since first recorded during Increment 1 (November 2001). The levels showed a downward trend throughout the Increments ranging from levels just above $65 \mathrm{dBA}$ (Increment 2) to levels slightly below $55 \mathrm{dBA}$ (Increment 24).

\section{Static location measurement}

After the 24-hour crew-worn measurements, the dosimeters were then deployed on day two for a 24-hour session at fixed locations. Static dosimetry measurements were conducted every 60 days. The acoustic dosimeters were cycled through each of the ISS pressurized modules or areas of concern, such as; exercise equipment, fans, etc. Measurements have been recorded in the US and Russian On-Orbit Segments. The data logging feature on the dosimeters were a great tool for assessing and evaluating changes, from continuous or intermittent sources of noise, in the environment.

An acoustic dosimeter was deployed in the Japanese Pressurized Module (JPM) starboard endcone to as sess the performance of an intra-module ventilation (IMV) fan. Figure 14 showed the trend of the acoustic levels for the starboard endcone in the JPM; intermittent noise levels have decreased by $2 \mathrm{dBA}$ during the period of March, 2009 to December, 2010. The continuous noise was shown to increase slightly between March 2009 and Dece mber 2010. The noise levels in the JPM returned to normal after the JPM starboard forward IMV fan flow straightener was cleaned on November 4, 2010. The IMV fans were part of the ISS Environmental Control and Life Support System (ECLSS) for driving air circulation between the pressurized modules. The IMV fan flow straightener or filter gets clogged with debris from ISS and stalled the fan which reduced the ventilation. As the IMV fan ventilation decreases, the noise level increases. This particular IMV fan pulled air from Node 2 into the JPM. The increase and decrease in noise levels caused by the IMV fan was evident in the changes to the continuous noise levels shown in figure 14. Data from the most recent sound level meter survey conducted in the same location have also confirmed the decrease in noise levels. 
A similar case was assessed in Node 2. The acoustic dosimeter was deployed in the Node 2 module on the starboard-side closeout panel, halfway up between the inlet on the floor and the ceiling linear diffuser outlets. Data had been collected in this location since Increment 16. As expected, the noise level in this location had decreased (as it did in JPM) to levels of 55-56 dBA, after clean ing (April 2009 - Increment 19) of the intra-module ventilation fan (IMV) filters between the US Lab and Node 2, see figure 15.

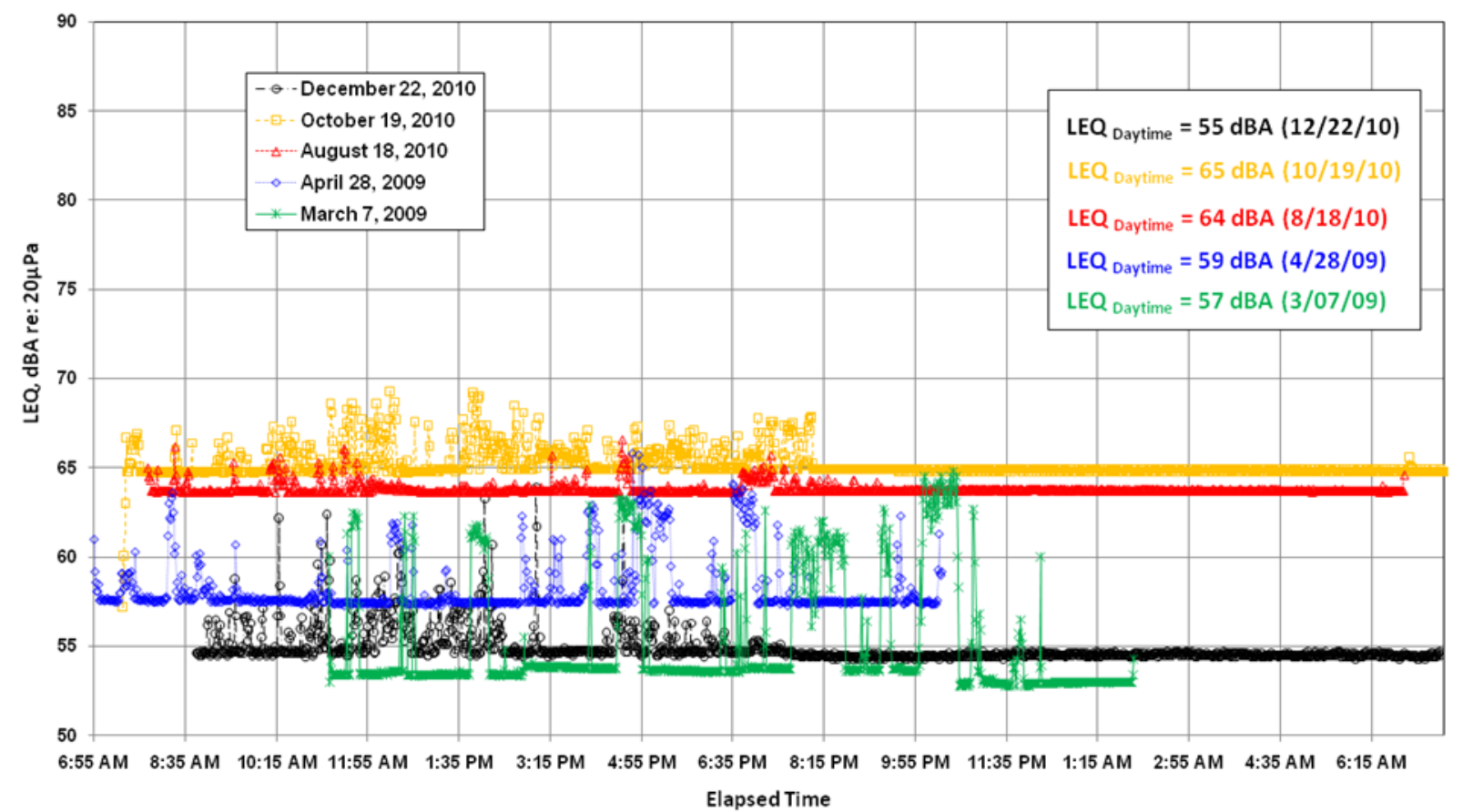

Figure 14. JPM Starboard Endc one (Acoustic Dosimeter Static Measurement).

\section{B. Uncertainty Analysis}

The ISO Standard 9612, "Acoustics Determination of occupational noise exposure - Engineering method", specified an engineering method for measuring workers' exposure to noise in a working environment and calculating the noise exposure level ${ }^{18}$. This standard was used for estimating the uncertainty on the crew-worn acoustic dosimetry measurements. First of all, the ISO Standard recommended defining homogenous noise exposure groups within the study population. The homogenous noise exposure groups were a group of workers (crewmembers) that were performing the same job and were expected to have similar noise exposure during the working day. As you recalled, crewmembers were exposed to different noise levels with regards to the work

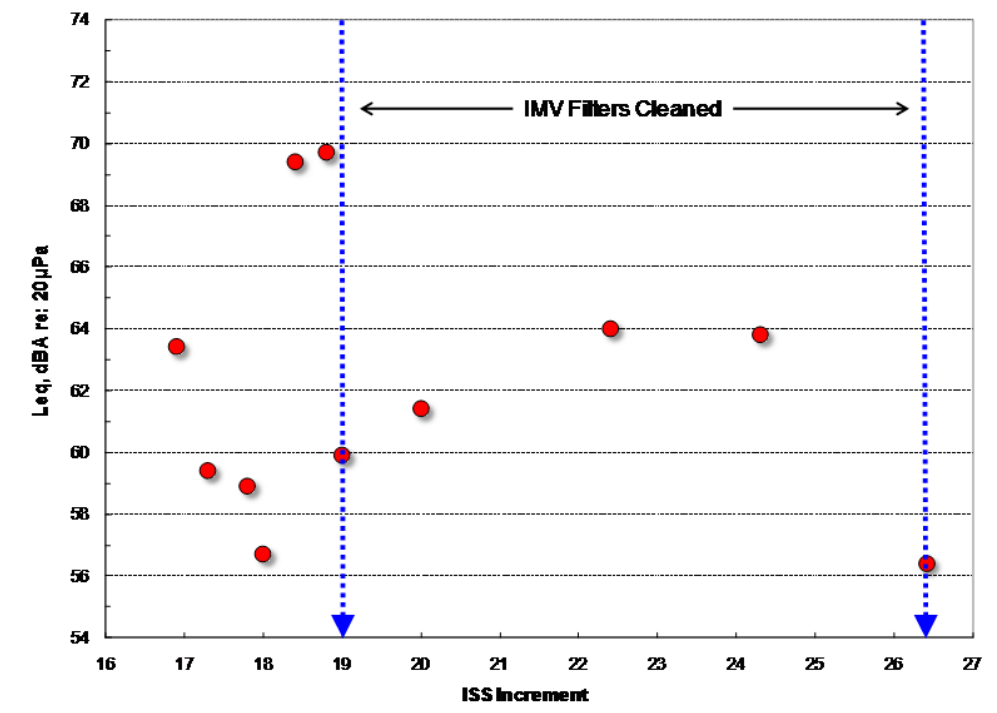

Figure 15. Node 2 Static Dosimetry $L_{\mathrm{EQ}}$ vs. ISS Increments. location. Crewmembers in the Russian On-Orbit Segments experienced higher noise levels than in any other ISS module. For simplicity and lack of data, the crewmembers were grouped by Increments instead of work location (USOS or ROS). During the early ISS stages, only three crewmembers were onboard for the period of the Increment as compared to six crewmembers. In

11

American Institute of Aeronautics and Astronautics 
an Increment, we can have as few as three or as many as twelve crew-worn measurements. In this case and for this reason, an Increment was considered a homogenous noise exposure group.

The standard also identified the main sources of uncertainty that can contribute to the results. These sources were: (1) variations in the daily work, operating conditions, uncertainty in sampling, (2) instrumention and calibration, (3) microphone placement, (4) false contributions, for example: airflows or impacts on the microphone and/or the microphone rubbing on clothes, (5) lacking or faulty work analysis, and (6) contributions from nontypical noise sources; speech, music alarm signals, and non-typical behavior. After identifying the sources of uncertainty, the evaluation of measurement uncertainties was completed. There were three measurement uncertainties that were calculated, $\mathrm{u}_{1}$ (standard uncertainty for sampling of job noise levels), $\mathrm{u}_{2}$ (standard uncertainty for the instrumentation used), and $\mathrm{u}_{3}$ (standard uncertainty due to measurement position). The three standard uncertainties were then used to calculate the combined standard ucertainty, $u$, and finally the expanded uncertainty, U. The standard also provided an Excel@ spreadsheet for performing the calculations. The equations and the spreadsheet used for calculating the standard uncertainties and the expanded uncertainty are discussed in detail in the ISO Standard 9612 and will not be discussed in this paper. Based on the calculations performed, the crewme mbers onboard ISS were exposed to a daily ( $\mathrm{L}_{\mathrm{EQ}-24}$ ) A-weighted range noise exposure level of 65 to $71 \mathrm{dBA}$, during Increments 1-26, with the as sociated expanded uncertainty for a one-sided coverage probability of $95 \%(\mathrm{k}=$ 1.65 ) of 2.2 to $6.1 \mathrm{dBA}$, see figure 16. The data showed that Increments 2-4 may have more than one homogenous noise exposure group; further analysis will be required in these three Increments (2-4).

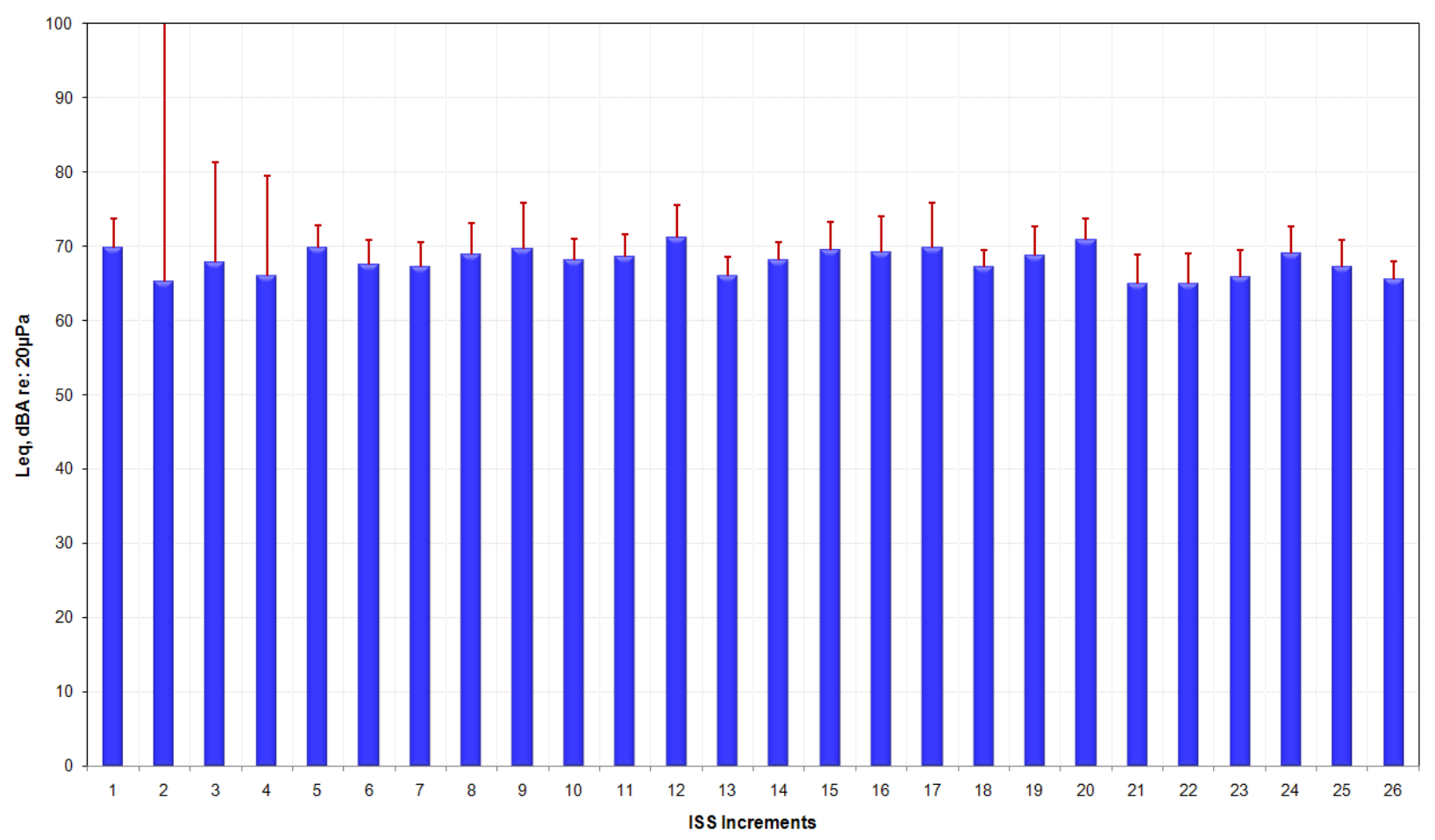

Figure 16. Crew-worn Average Daily Noise Exposure Level, including Expanded Uncertainty (U).

\section{Dis cussion}

This paper described the noise exposure monitoring program as well as an assessment of the acoustic dosimeter data collected to date. Acoustic data onboard ISS had been collected since it was occupied by three crewmembers on November 2001 (Increment 1). The data collected from Increments 1 through 16 does not include logging data, it just provided one number per measurement session and required the crew to provide hand-tabulation of data which then was called down to Mission Control. This is the first time that this acoustic dosimetry data has been published as a complete dataset. 
The data provided trending information with regard to the work and sleep environments experienced by the crewmembers on ISS. The work environment average noise level tended to remain slightly constant, fluctuating between 67 to $73 \mathrm{dBA}$, with higher levels recorded in the Russian On-Orbit Segments. In contrast, the sleep environment average noise level has declined, highlighted by approximately $10 \mathrm{dBA}$ decreased in the noise levels in the Kayutas located in the Russian Service Module. However, the average noise level for the full-day tracked the levels and variations seen in the work environment data log. Based on this observation and the ISS Flight Rule, the crewme mbers on ISS have been required to wear hearing protection devices (HPDs) 64\% of the time, throughout all 26 Increments, see figure 17. Though, during Increments 1-13, the crewme mbers were required to wear HPDs $70 \%$ of the time and during Increments $14-26,60 \%$ of the time. Overall, there has been an improvement in the acoustical environment on ISS. These measurements were highly dependent on the activities/tasks the crew on ISS, whether occupational or leisure, have been engaged during their stay on ISS. The sleeping crew quarter noise levels can vary depending on many factors such as where is the crew quarter located (US or Russian On-Orbit Segments), if the crew quarter's door is opened or closed, and if the crewmember used a fan (what speed?) or listened to music or watched movies. Many of these factors can contribute to the variance seen in the measured data. Better understanding on the factors will provide a better understanding on the contribution that each factor can add to the overall noise exposure level.

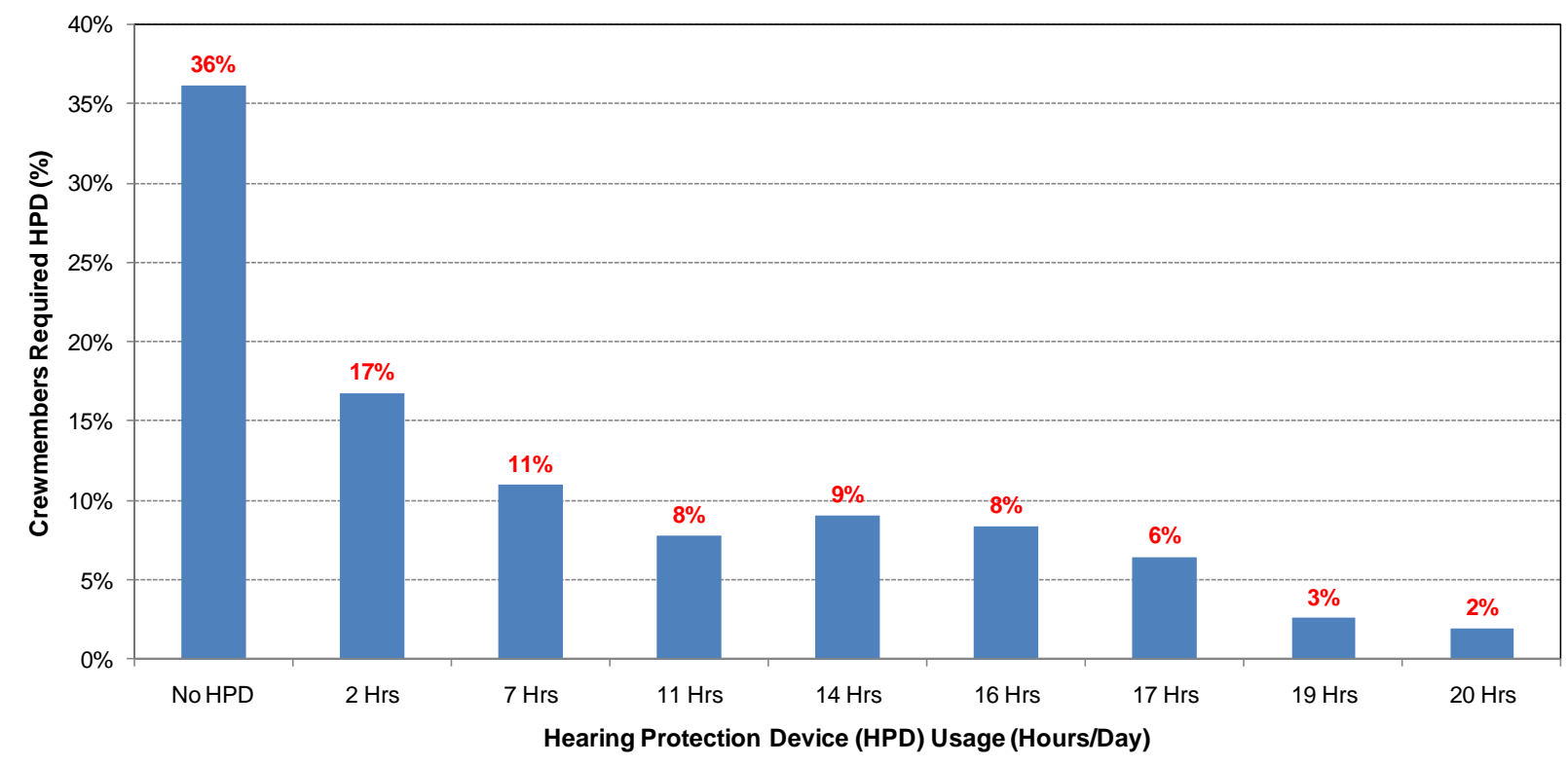

Figure 17. Hearing Protection De vice (HPD) Us age on ISS (Increments 1-26).

The static dosimetry data has proven to be an excellent asset for evaluating hardware or payload performance, for example: clogged IMV fans filters, and can also assist as a preventative maintenance guide by providing correlation as to when maintenance should be performed, so as to schedule the maintenance activity. This data can also serve as an environmental data point or spot check for validating crew-worn dosimetry data. Having an environmental data point will help in calculating the uncertainty of the dataset and will provide a better representation of the noise exposure environment. Understanding the acoustical environment is vital for all space programs. Even though the data suggests an improvement in the environment, hearing loss has been documented in long-duration spaceflights. For example, one of the seven US crewmembers who flew on the Mir Space Station returned with a temporary threshold shift $(\mathrm{TTS})^{19}$. Data from the Russian Space Program on long-duration space flights (i.e. Salyut and Mir) reported TTS and in some cases permanent threshold shifts (PTS) on some of their cosmonauts ${ }^{20}$. A Russian longduration ground study showed that continuous exposure to levels of $75 \mathrm{dBA}$ can lead to $\mathrm{TTS}^{21}$. However, during short-duration space flights, e.g. Space Shuttle program, clin ically significant temporary and permanent threshold shifts were not observed on the crewmembers ${ }^{20,22,3}$. Lessons learned from past space programs have shown to be very beneficial to the ISS Program. 


\section{Future Directions}

The crewmembers on ISS have several modules in which they can spend time during the day. Accurately tracking their activities, tasks, and noise exposure in these modules is a task all by itself. The current dosimeters used onboard ISS have the capability for recording and data logging in one-minute intervals. However, correlating crew activities to recorded data can be a difficult task unless a crewmember's timeline is well defined with time stamps corresponding to completed activities. Currently, this correlation between the recorded data and crew timeline is lacking. An activity is being planned for collecting on-orbit data that will provide a basis for a noise hazard mapping of areas and activities on ISS that contribute significantly to the noise exposure experienced by the crew. Presently, hearing protection requirements are based on 24-hour noise exposure measurements which provide little information as to the cause of the exposure (ISS Flight Rule). As a result, hearing protection usage is specified as hours per day with no consideration for when (according to acoustic loading) the hearing protection would be most effective. The Noise Hazard Inventory (NHI) will provide a correlation between noise exposure increments and identified activities and locations so that informed recommendations for when the crew should wear hearing protection can be made. In addition, the data will be analyzed to determine sources of excessive noise and indicate need for future noise mitigations. The information, gathered through implementation of a data logging activity, will be correlated on the ground with the time-dependent sound levels measured by the current acoustic dosimeters, and the NHI will be developed. The NHI will reduce the risk for noise-induced hearing loss, and will improve voice communications by avoiding non-productive mandated hearing protection use. The NHI will be used for implementing a new acoustic flight rule that is based on a "task-based" hearing conservation approach. Task-based methods have distinct advantages over full-shift methods in that they provide a better understanding of sources of high noise exposure ${ }^{24,25}$.

Another area that needs great consideration is crewtime allocation for maintenance tasks. As ISS moves from Assembly Complete to a National Research Laboratory, less and less crewtime will be available for performing nominal environmental monitoring tasks. The crew on ISS will be very busy performing research activities. An automated system will be required for monitoring sound pressure and noise exposure levels in long-duration space vehicles. The automated system should require little to no crew interaction for normal operations thus freeing up time for scientific research.

\section{Conclusions}

Crew-worn acoustic dosimetry data have been collected onboard ISS since November 2001, when the ISS was first occupied by the first three crewmembers. Data has shown that acoustic requirements at all levels and noise control mitigations have produced a decrease in sleep-time noise exposure levels, by approximately $10 \mathrm{dBA}$ in the Kayutas crew quarters. The requirement for the crew to use hearing protection devices has also decreased from $70 \%$ to $60 \%$ of the time, based on the $24-\mathrm{hr}$ noise exposure level measurements and the current ISS Flight Rule. Static dosimetry has also helped identify hardware anomalies. Overall, there has been an improvement in the acoustical environment on ISS. These dosimetry measure ments which are highly dependent on the activities/tasks the crew on ISS, whether occupational or leisure, have been captured during their stay on ISS. As we learned how to better correlate the crew timeline with the recorded acoustic dosimetry data, our ability to protect the crewmembers onboard ISS will be enhanced.

\section{Acknowledgments}

The authors would like to thank the ISS Biomedical Engineers for helping with the crew procedures, training, anomaly resolutions and serving as the liaison to the ISS crew; the hardware engineers for keeping the acoustic dosimeters certified and ready for flight; the JSC Audiologist for his guidance and partnership on the NASA Hearing Conservation Program; and the International Partners for their collaboration with the noise exposure monitoring program. We would also like to thank the ISS crewmembers for their support and understanding of the need for this noise exposure data. 


\section{References}

${ }^{1}$ Kitmacher, G. H., Gerstenmaier, W. H., Bartoe, JD. F., and Mustachio, N., "The international space station: A pathway to the future," Acta Astronautica, Vol. 57, 2005, pp. 594-603.

${ }^{2}$ SSP 50260, "International Space Station Medical Operations Requirements Document (MORD)," February 2006.

${ }^{3}$ JSC 28913, "Medical Requirements Integration Document (MRID)," Rev A, March 2005.

${ }^{4}$ SSP 50260-1, "ISS Generic Groundrules, Requirements and Constraints (GGR\&C), Part 1: Strategic and Tactical Planning," Rev E, January 2011.

${ }^{5}$ SSP 50260-2, “ISS Generic Groundrules, Requirements and Constraints (GGR\&C), Part 2: Execute Planning," Rev C, February 2011.

${ }^{6}$ SSP 54025_54026-ANX 4, "Increment Definition and Requirements Document (IDRD) for Increments 25 and 26, Anne x 4 : Medical Operations and Environmental Monitoring," May 2010.

${ }^{7}$ NSTS-1282, "ISS Generic Operational Flight Rules," Vol. B, B13-152, "Noise Level Constraints."

${ }^{8}$ Allen, C. S., and Goodman, J. R., "Preparing for Flight - The Process of Assessing the ISS Acoustic Environment," NOISECON 2003 Conference, Cleveland, OH, 2003.

${ }^{9}$ Beranek, L. L., and Ver, I. L., Noise and Vibration Control Engineering Principles and Applications, $2^{\text {nd }}$ ed., John Wiley \& Sons, Inc., 2006, Chap. 20.

${ }^{10}$ Goodman, J. R., "International Space Station Acoustics," NOISE-CON 2003 Conference, Cleveland, OH, 2003.

${ }^{11}$ Pilkinton, G. D., "ISS Acoustics Mission Support," NOISE-CON 2003 Conference, Clev eland, OH, 2003.

${ }^{12}$ JSC 64690, "Project Requirements and Verification Document (PR\&VD): Plan and Report for the Intravehicular Activity (IVA) Non-Critical Hearing Protection Kit (HPK),” Basic, June 2009.

${ }^{13}$ Baggerman, S. D., Rando, C. M., Duvall, L. E., "Habitability and Human Factors: Lessons Learned in Long Duration Space Flight". Proceedings of the American Institute of Aeronautics and Astronautics Space 2004 Conference Exhibit. San Diego, Calif., Sep 2004.

${ }^{14}$ OSHA Standard, "Occupational Noise Exposure," 29 CFR 1910.95.

${ }^{15}$ NIOSH, "Preventing Occupational Hearing Loss - A Practical Guide," No. 96-110, June 1996.

${ }^{16}$ William, S., "ISS CU CQ Consideration of Previous Crew Accommodations," Engineering Memo No. CQ-06-045A, August 8, 2006.

${ }^{17}$ Minton, J., and Katz, M. A., "Crew Quarters, Sleep, and Privacy Comments from Phase 1 NASA-Mir U.S. Crewmember Debriefs," LMSMSS 32848, July 1998.

${ }^{18}$ ISO Standard, "Acoustics - Determination of occupational noise exposure - Engineering method," ISO 9612, Second Edition, 2009-04-01.

${ }^{19}$ Buckey, J. C., Musiek, F. E., Klein-Schoder, R., Clark, J., Hart, S., and Havelka, J., "Hearing Loss in Space," Aviation, Space, and Environmental Medicine, Vol. 72, No. 12, December 2001, pp. 1121-1124.

${ }^{20}$ Clark, J. B., and Allen, C. S., “Acoustic Issues,” Principles of Clinical Medicine for Space Flight, $1^{\text {st }}$ ed., Springer, 2008, Chap. 24.

${ }^{21}$ Hodge, D. C., and Garinther, G. R., "Noise and Blast,” Bioastronautics Data Book, $2^{\text {nd }}$ ed., NASA SP-3006, 1973, Chap. 15 .

${ }^{22}$ Roller, C. A., and Clark, J. B., "Short-duration space flight and hearing loss," Otolaryngology - Head and Neck Surgery, July 2003, pp. 98-106.

${ }^{23}$ Koros, A. S., Adam, S. C., Wheelwright, C. D., "Noise Levels and their Effects on Shuttle Crewmembers' Performance: Operational Concerns," N94-11538, 1994.

${ }^{24}$ Seixas, N. S., Ren, K., Neitzel, R., Camp, J., and Yost, M., "Noise Exposure among Construction Electricians," AIHAJ, Vol. 62, 2001, pp. 615-621.

${ }^{25}$ Seixas, N. S., Sheppard, L., and Neitzel, R., "Comparison of Task-Based Estimates with Full-Shift Measurements of Noise Exposure," AIHA Journal, Vol. 64, 2003, pp. 823-829. 